\title{
Cuidadores de idosos: percepção sobre o envelhecimento e sua influência sobre 0 ato de cuidar $^{1}$
}

\section{Senior caretakers: perception about aging and its influence on the nursing act}

\section{Aline Melo Oliveira Sampaio*}

Centro de Atenção Psicossocial - CAPS, Governador Valadares, MG, Brasil

\section{Fernanda Nunes Rodrigues **}

Universidade Vale do Rio Doce - UNIVALE, Governador Valadares, MG, Brasil

\section{Valquiria Gonçalves Pereira***}

Universidade Vale do Rio Doce - UNIVALE, Governador Valadares, MG, Brasil

\author{
Suely Maria Rodrigues**** \\ Universidade Vale do Rio Doce - UNIVALE, Governador Valadares, MG, Brasil
}

\section{Carlos Alberto Dias*****}

Universidade Vale do Rio Doce - UNIVALE, Governador Valadares, MG, Brasil

\begin{abstract}
RESUMO
A percepção dos cuidadores de idosos institucionalizados sobre o envelhecimento pode influenciar nos cuidados prestados aos idosos. Objetivando conhecer tal percepção, realizou-se uma entrevista estruturada com 26 cuidadores das cinco Instituições de Longa Permanência do município de Governador Valadares - MG. Em seguida, procedeu-se a uma análise dos dados coletados, na qual identificou-se que a maioria dos participantes $(92,3 \%)$ recebeu alguma formação para atuar nesse campo somente após a contratação. Das atividades realizadas pelos cuidadores, $80,8 \%$ estão direcionadas às necessidades básicas dos internos. Ao definirem o ser idoso $(53,8 \%)$ o fazem de forma negativa. Observou-se que a percepção do cuidador acerca do envelhecimento exerce significativa influência sobre o seu ato de cuidar. Conclui-se que a falta de preparação e de atenção especializada dirigidas a esses profissionais cuidadores, contribui para um serviço sem qualidade dirigido ao idoso, comprometendo também a qualidade de vida do próprio cuidador.

Palavras-chave: Idoso institucionalizado, Cuidadores, Percepção,
\end{abstract} Envelhecimento.

\begin{abstract}
The perception of the institutionalized senior caretakers about aging, may influence on the cares given to the elderly. Aiming the knowledge of such perception, it took place a structured interview with 26 professionals of this area, from the five Long Term Institutions in Governador Valadares, MG.
\end{abstract}


Afterwards, it was made an analysis of the data, where it was identified that the most part of the participants $(92,3 \%)$ have received preparation only after being admitted. Among the nursing duties, $80,8 \%$ concerns the interns' basic needs. Defining the senior being, $(53,8 \%)$ do it in a negative way. In conclusion, the caretakers' perception about the aging exerts a meaningful influence on the nursing act. The lack of preparation and attention to the caretaker professionals, contributes to a service without quality addressed to the elderly, compromising, also, the own caretaker quality of life.

Keywords: Institutionalized senior, Caretakers, Perception, Aging.

\section{Definição do ser idoso e epidemiologia do envelhecimento no Brasil}

Na França do século XIX, utilizava-se o termo "velho" para nomear indivíduos desprovidos de bens, os mais necessitados ou indigentes. Com esse termo tratava-se de forma pejorativa as pessoas que tinham certa incapacidade para o trabalho. Em contrapartida, os que possuíam uma boa posição social, capacidade de governar seus bens e usufruir de respeito, eram denominados "idosos". Embora o termo idoso já fosse empregado no Brasil nesse mesmo período, foi devido à influência francesa que o mesmo passou a ser utilizado em documentos oficiais (SALIBA; MOIMAZ; MARQUES; PRADO, 2007).

É comum utilizar a palavra senescente como sinônimo de idoso. $O$ termo senescente é derivado da palavra senescência, que significa conjunto de alterações normais do envelhecimento, que ocorrem desde aspectos funcionais do organismo até os psicológicos do indivíduo. Entretanto, senescência não deve ser confundida com "senilidade" que se refere às alterações ocorridas no organismo, porém derivadas de afecções que acometem os idosos (NETTO, 2006).

Segundo a Organização Mundial de Saúde (OMS, 1983), a população da terceira idade é classificada de acordo com o desenvolvimento do país de origem. Nos países desenvolvidos, são considerados idosos aqueles que possuem idade igual ou superior a 65 anos, enquanto nos países em desenvolvimento o limite fixado é de 60 anos, sendo esse o caso do Brasil.

Mesmo sendo a definição cronológica útil para delimitar aqueles que podem ser denominados idosos, ainda assim esse critério não é consensual. As definições bem como as representações sociais em relação ao idoso e ao processo de envelhecimento variam de acordo com a história, o local e a época em que são gestadas. Em outros termos, o processo de envelhecimento e o tornar-se idoso dependem bastante de variáveis de ordem biológica, social, intelectual, econômica, funcional e cronológica (PASCHOAL, 2002).

De acordo com o Instituto Brasileiro de Geografia e Estatística (IBGE), o Brasil está entre os dez primeiros países do mundo que 
possuem maior população com idade igual ou superior a 60 anos (BRASIL, 2007). Segundo J orge, Laurenti, Lima-Costa, Gotlieb e Filho (2008), em 1980, os idosos brasileiros correspondiam a $6,1 \%$ dos habitantes, já no censo de 1991 passaram a representar 7,3\% da população, no censo de $2000,8,6 \%$, e em 2005 , os idosos chegaram a representar $10 \%$ dos habitantes. A estimativa para o ano de 2020 é de que essa população chegue a 30,9 milhões (BELTRÃO et al. apud LIMA-COSTA; CAMARANO, 2008).

Lima-Costa e Camarano (2008) afirmam que tal crescimento é resultado da alta taxa de natalidade constatada nos anos 50 e 60 em comparação à baixa taxa de natalidade nos dias atuais, o que fez alterar consideravelmente a distribuição etária da população no Brasil. Outro fator influenciador nesse crescimento é a redução da mortalidade, o que pode ser percebido no aumento da expectativa de vida dos idosos.

Analisando os dados citados, pode-se dizer que existe maior proeminência de vida para o sexo feminino da população idosa. As mulheres correspondem a $55 \%$ do total dos idosos. Tal proporção se deve ao alto grau da mortalidade na população masculina. No entanto, apesar de viverem mais tempo que os homens, as mulheres atuais enfrentam maiores dificuldades durante essa fase da vida. Costumam apresentar-se numa situação econômica precária, decorrente do histórico profissional que possuem, visto que muitas delas não exerceram atividades remuneradas durante a juventude e a idade adulta (LIMA-COSTA; CAMARANO, 2008).

Em contrapartida, as mulheres se mostram mais adaptáveis do que os homens fora do mercado de trabalho. Participam de atividades extras, temporárias, mas remuneradas, o que as transformam depois de algum tempo nas próprias provedoras da família. Elas também destoam dos homens no que se refere ao estado civil. Em pesquisa realizada pelo IBGE no ano de 2000 sobre a distribuição percentual dos idosos em quatro classes conjugais (solteiros, casados, separados e viúvos), constatou-se um percentual maior de mulheres viúvas em comparação aos homens. Esse fator está relacionado à maior longevidade das mulheres e ao segundo casamento que é mais frequentemente observado entre os idosos do gênero masculino. As mulheres estão mais propensas a não envolver-se em novo relacionamento conjugal, mantendo o status de viúvas (LIMA-COSTA; CAMARANO, 2008).

Ainda sobre o envelhecimento populacional no Brasil, vale ressaltar as alterações ocorridas dentro do próprio grupo etário. Tem-se observado um significativo aumento no número de idosos com idade acima de 80 anos. Entre 1991 e 2000, os octogenários chegaram a representar um crescimento anual de $5,4 \%$. Tal segmento atingiu, em 2000, o percentual de $12,6 \%$ do total da população idosa 
brasileira. Isso significa que também a população de idosos está "envelhecendo" (LIMA-COSTA; CAMARANO, 2008).

Diante dessa perspectiva, torna-se importante refletir sobre os serviços que dão suporte ao idoso. De acordo com Pellegrini e J unqueira (2002), os serviços de atenção à saúde do idoso devem ser planejados visando um atendimento mais abrangente. Existem princípios fundamentais que devem servir de base para a formação de ações destinadas aos idosos, como a preocupação em proporcionar uma maior capacidade funcional e independência física e mental no meio social e familiar. Nesse aspecto, promover saúde significa criar estratégias com intuito de diminuir 0 índice de adoecimento e mortalidade (BRITO; RAMOS, 2002).

É preciso que tal objetivo se faça presente no ambiente familiar ou institucional em que o idoso está inserido. Já que existem instituições procurando melhorar suas estruturas para atender adequadamente a população. Apesar de que, segundo Born (2002), o melhor caminho para o idoso é estar no seio familiar, convivendo com seus entes queridos, com quem passou a maior parte de sua vida. Tal consideração pode ser sustentada pelo exemplo da Ásia, descrito por Friedan (1993), onde o caminho para institucionalizar o idoso é visto como último recurso. Nos países asiáticos, a política governamental impõe limites ao acesso de assistência institucional, o que dificulta o descaso e o abandono por parte da família.

\section{O idoso institucionalizado}

Historicamente, grande parte das instituições de longa permanência possui um perfil assistencialista, no qual, prestar cuidados aos idosos resume-se a oferecer abrigo e alimentação a pessoas em situação de pobreza, com problemas de saúde e sem suporte social. Porém, uma nova prática tem sido preconizada, na qual o cuidar envolve o acesso ao atendimento de profissionais de saúde capacitados, condições de espaço físico e ambiental apropriados, disponibilização de atividades de lazer e contato social com a comunidade (POLLO; ASSIS, 2008).

Atualmente, os determinantes da institucionalização têm sido mais bem conhecidos através de estudos sobre o perfil das ILPIs e do público atendido, características e necessidades das instituições. Uma ILPI "deve procurar ser uma residência, mostrando, tanto nos seus aspectos físicos quanto em toda a sua programação, detalhes que lembrem uma casa, uma moradia, a vida numa família" (BORN; BOECHAT, 2002).

A Portaria no 810/1989 foi a primeira a definir as Normas e Padrões de Funcionamento de Casas de Repouso, Clínicas Geriátricas e outras instituições para idosos. Fica definido como deve ser a organização da instituição, a área física, as instalações e os recursos humanos (BRASIL, 1989). No processo de regulamentação da Política Nacional do Idoso, a Portaria no 73/01 trouxe uma nova definição de Normas e 
Padrões de Funcionamento para Serviços e Programas de Atenção à Pessoa Idosa, adotando o termo Atendimento Integral Institucional (BRASIL, 2001).

Em 2005, passa a vigorar a Resolução da Diretoria Colegiada (RDC no 283). A RDC adota o termo ILPI e estabelece normas de funcionamento dessa modalidade assistencial. Segundo o documento, ILPIs são "instituições governamentais ou não-governamentais, de caráter residencial, destinadas a domicílio coletivo de pessoas com idade igual ou superior a 60 anos, com ou sem suporte familiar, em condições de liberdade, dignidade e cidadania". A norma define quais são os graus de dependência e as condições gerais de organização institucional baseadas nos direitos dos idosos, incluindo recursos humanos, infraestrutura, processos operacionais, notificação compulsória, monitoramento e avaliação. A implementação desse documento é um desafio para os órgãos fiscalizadores e as instituições. Constantemente, estas estão sendo obrigadas a adequarem-se à legislação, superando o paradigma de atendimento, enquanto caridade e assistencialismo, para 0 de prestação de serviços com qualidade e garantia dos direitos da pessoa idosa (ANVISA, 2005).

Com relação à localização, propõe que o ideal é possibilitarem o fácil acesso a transportes e a rede de serviços, garantirem a segurança da instituição, dos profissionais e dos usuários. A disposição arquitetônica deve respeitar a individualidade e propiciar espaços para convivência que lembrem residências, com cores claras e variadas, móveis e utensílios que ofereçam conforto, higiene e segurança. $O$ padrão de qualidade no atendimento institucional deve se pautar na valorização da história do idoso, no respeito à sua individualidade, autonomia e privacidade, na preservação dos vínculos e na participação na comunidade. A assistência religiosa deve ser oferecida de acordo com a crença para aqueles que desejarem. Ao idoso deve ser permitido levar pequenos objetos de uso pessoal e a ele deve ser apresentada a instituição, seus horários e rotinas, numa abordagem que transmita segurança e sensação de acolhimento. Para os idosos que perderam a autonomia e/ou independência, é fundamental que possam sair do leito, tomar sol, ter acesso à área externa e, se possível e conveniente, participar de atividades de socialização (BORN; BOECHAT, 2002).

O documento pressupõe ainda, a provisoriedade da institucionalização e aponta a necessidade de serviços que ampliem a porta de saída dos abrigos, tais como apoio à moradia, reinserção familiar, alfabetização, centros-dia, centros de convivência, repúblicas, programas de transferência de renda para as famílias permanecerem com seus idosos, retorno à cidade de origem, qualificação profissional, programas de geração de renda e inserção no mercado de trabalho e programas habitacionais (HERÉDIA, 2004). 
Para oferecer um atendimento de qualidade, também é fundamental que as instituições assegurem aos profissionais o espaço para supervisão, estudos e reuniões. Além da qualificação continuada, esse contato é importante para que os profissionais possam dividir suas dúvidas, angústias e anseios (SILVA, 2005).

\section{Perfil do profissional cuidador}

Sabe-se que, com o passar dos anos, o indivíduo sofre normalmente algumas alterações em seu estilo de vida que podem ter origem fisiológica, genética, ambiental ou mesmo emocional (BERGER, 2003).

Essas mudanças compõem uma fase natural no desenvolvimento humano. Entretanto, no caso de indivíduos idosos, poderão ocorrer transformações mais severas em seu estado funcional. Isto faz emergir a necessidade de alguém para auxiliá-los no exercício de atividades que antes eram desempenhadas normalmente. É devido a esta demanda específica que surge o papel do cuidador (SALIBA; MOIMAZ; MARQUES; PRADO, 2007).

Para situar o cuidador enquanto profissional, Duarte, Melo e Azevedo (2008) ressaltam o fato de que a profissão de cuidador só foi reconhecida recentemente no País:

O surgimento do cuidador profissional é fato recente no Brasil, cuja função está consolidada pelo Ministério do Trabalho e Emprego, através de reconhecimento e inserção na Classificação Brasileira de Ocupações, sob o código 5.16210 (cuidador de idosos dependentes ou não e cuidador de idosos institucionalizados). Apesar do crescimento dessa categoria profissional, existem poucas iniciativas no campo da educação formal que contribuam para a sua consolidação. Não há critérios definidos ou pré-requisitos estabelecidos para regulamentar a formação desses profissionais (DUARTE; MELO; AZEVEDO, 2008, p. 373).

Poder-se-ia dizer que o cuidador ideal seria aquele com conhecimento em diversas áreas da saúde, podendo ser compatível com a diversidade de aspectos trazidos pelo processo natural do envelhecimento. Nessa perspectiva, também é valorizado o cuidador que compartilha seus conhecimentos técnicos com outros profissionais, o que contribui para a melhoria do trabalho em equipes multidisciplinares (FILHO; SITTA, 2002). Duarte, Melo e Azevedo (2008) salientam que esse tipo de trabalho é realizado em muitos países desenvolvidos, sendo o cuidador de idosos um dos integrantes da equipe de profissionais da saúde.

Capacitar profissionais para atender as necessidades de saúde do idoso é uma das diretrizes estabelecidas pela Política Nacional de Saúde do Idoso - PNSI (BRASIL, 1999). Mesmo que o termo cuidador de idosos não esteja especificado na normatização, ele é considerado 
como estando entre os profissionais a serem qualificados. Ressalta-se que tal medida tem como objetivo principal auxiliar e promover o idoso para o seu bem-estar físico e emocional (RIBEIRO; FERREIRA; FERREIRA; MAGALHÃES; MOREIRA, 2008).

A necessidade de capacitar o profissional de saúde que trabalha com idosos é, inegavelmente, percebida e declarada no Brasil, sendo preconizada pelas políticas de atenção ao idoso. A necessidade real da capacitação está inserida nas diretrizes da Política Nacional de Saúde da Pessoa Idosa, uma vez que, estimula a formação dos profissionais de saúde como uma estratégia para atenção à saúde do idoso (BRASIL, 2006).

Segundo essa política, para prestar assistência ao idoso, o profissional de saúde necessita desenvolver habilidades e competências específicas para que seja capaz de diferenciar os idosos das demais faixas etárias. No processo de capacitação, a implementação de cursos de aperfeiçoamento em envelhecimento e saúde da população idosa, desempenhará um papel fundamental neste processo, visando alcançar o grande desafio: prestar um cuidado humanizado, competente, ético e que propicie um envelhecimento ativo e saudável, com dignidade e qualidade de vida. Apesar disso, é notória a falta de capacitação do cuidador. É possível dizer que as políticas ou ideias de formação e atenção ao cuidador são criadas sem possuir, até o momento, o suporte de autoridades dotadas de poder que sejam capazes de fazer executá-las.

Não existem, ainda, pré-requisitos que regulamentem de forma precisa a formação do cuidador. De acordo com Born (2006), são poucas as ações criadas pelo poder público que dão apoio concreto aos cuidadores. Nacionalmente, algumas foram iniciadas, porém interrompidas e perderam verbas públicas.

\footnotetext{
Instituições de longa permanência para idosos vêm empregando cuidadores com ou sem qualificação. A Resolução da Diretoria Colegiada 283, que aprovou, em setembro de 2005, o Regulamento Técnico para o Funcionamento das Instituições de Longa Permanência para Idosos, no artigo 4.6.1.2., referente a recursos humanos para cuidados ao idoso, especifica o número de cuidadores que uma ILPI deverá possuir em função do grau de dependência e número de idosos, mas não esclarece a qualificação exigida (BORN, 2006).
}

Observa-se, portanto, que na atualidade, o processo para qualificar cuidadores é considerado difícil. Depende-se de uma complexidade de fatores, dentre os quais: leis que deem suporte a esse trabalhador e o investimento das instituições de longa permanência nesse processo. As instituições geralmente não requisitam aspectos considerados 
essenciais ao candidato no ato de sua contratação, o que, como foi dito, não está previsto na sua própria regulamentação.

Sabe-se que devido ao despreparo, a falta de recursos técnicos e de suporte na vida pessoal, o cuidador se submete à jornadas intensas de trabalho recebendo baixas remunerações. Ressalta-se nesse mesmo contexto a presença de mulheres cuidadoras, não diferentemente dos demais profissionais, estão expostas ao desgaste físico, estresse, ansiedade, decréscimo nas participações sociais entre outros. Os assistidos, no caso os idosos, também são afetados pelo mal estar do cuidador. O profissional ao ter sua saúde debilitada tende a se distanciar do idoso, se mostrando indiferente a ele, o que pode levá-lo às vezes ao abandono do trabalho (NERI; CARVALHO, 2002).

Diante de tal situação é possível pensar que sentimentos simultâneos como satisfação e desprazer formam um atributo patente da rotina de trabalho do cuidador. Uma experiência que costuma ser gratificante pode ser ao mesmo tempo desgastante, cuja tendência é considerar que a profissão do cuidador é tributária da fragilidade ou incapacidade declarada pelo indivíduo idoso. Uma situação delicada, na qual o sofrimento de ambas as partes se faz presente.

De um lado o idoso, que passa a perder aos poucos sua identidade e autonomia porque deixa de efetuar, por exemplo, cuidados básicos de sua vida cotidiana. Por outro lado, o cuidador que tem sua vida dedicada a dar atenção integral àquele que é assistido. Desse modo se faz necessário direcionar a atenção e suporte a esse profissional, com o intuito do mesmo possuir qualidade de vida e poder proporcioná-la aos que por ele são assistidos.

\section{A expectativa sobre $o$ ato de cuidar}

A palavra "cuidar", na língua portuguesa, significa aplicar a atenção, o pensamento, a imaginação. Refere-se também ao ato de ter cuidado de forma geral e, mais especificamente, consigo mesmo. Segundo Saliba, Moimaz, Marques e Prado (2007), esta palavra pode denotar também uma ação dinâmica, refletida, pensada. Já o termo "cuidado é, na verdade, o suporte real da criatividade, da liberdade e da inteligência" (DUARTE; MELO; AZEVEDO, 2008, p. 372).

Entende-se nesse estudo que cuidar não é apenas um ato, mas uma atitude. A esse respeito vale referendar o teólogo e filósofo Leonardo Boff, segundo o qual:

[...] nós cuidamos de nossa casa, subentendemos múltiplos atos como: preocupamo-nos com as pessoas que nela habitam dando-Ihes atenção, garantindo-lhes as provisões e interessando-nos com o seu bem-estar. Cuidamos da aura boa que deve inundar cada cômodo, o quarto, a sala e a cozinha $[\ldots]$ (BOFF, 1999, p. 33). 
Refletindo sobre esses aspectos do cuidar, Boff (1999) entende tal atitude como natural do ser. A maioria dos indivíduos, com condições normais e saudáveis de sobrevivência, tem a consciência de que para viver com qualidade, é necessário zelar pelos seres que constituem seu hábitat, ou seja, aqueles considerados relacionáveis. Fazemos tudo isso porque somos simplesmente humanos e temos 0 autocuidado como símbolo da nossa condição humana (BOFF, 1999). Partindo-se do princípio de que o cuidado é inerente a tudo que é humano, faz-se referência ao cuidado da mãe tido como natural em relação ao seu bebê. Um natural, que como arrisca dizer Campos (2006), talvez seja instituído por um desejo que surge antes mesmo da gestação, o desejo de se ter um filho. Com base na teoria de Winnicott (1982), que descreve o significado de cuidar nessa relação, estima-se que o ato de cuidar na relação cuidador-cuidado, seja representado pelo mesmo "holding", ambiente acolhedor e facilitador que a "mãe suficientemente boa" possibilita ao seu bebê.

A "mãe suficientemente boa" descrita por Winnicott (1999) refere-se àquela capaz de captar e atender as necessidades essenciais ou iniciais do filho de forma sentida, e não expressa em palavras já que o bebê (infante) não verbaliza. O autor quer enfatizar a mãe que "comumente" dá atenção ao seu bebê. A sensibilidade da mãe é essencial nesse processo e também tem relação com a identificação que esta faz com o seu filho.

O "holding" é um dos pilares da teoria do desenvolvimento por Winnicott (1999) que abrange os aspectos anteriormente mencionados. Trata-se do "ambiente de facilitação" ao "processo de maturação" do bebê; é o conjunto de cuidados dedicados pela mãe, que dá ao "infante" a oportunidade de ser, para em seguida ajudá-lo a firmar em sua capacidade de sentir-se real, de lidar com o mundo externo, favorecendo o seu desenvolvimento psicológico.

Não obstante as referências acima destacadas, ainda há inúmeras compreensões equivocadas que se formam em torno do sentido do cuidado e que podem determinar sua qualidade. Em estudo realizado com cuidadores para análise de interações com idosos (PAVARINI apud NÉRI; CARVALHO, 2002) observou-se que esses profissionais praticavam o cuidado "em lugar do idoso". A autora destaca que os cuidadores observados não entendiam o cuidado como uma promoção da autonomia, e nem estimulavam a independência quando se tratava de um idoso sem dependência total (NERI; CARVALHO, 2002).

Tal situação se apresenta de forma contraditória ao que se percebe do ponto de vista winnicottiano, cuja ideia defendida pelo autor baseia-se no fato de que o ato de cuidar deve-se constituir apenas na produção de um ambiente que facilite o processo de desenvolvimento da criança. E nesse sentido, não deve ser a mãe o elemento principal desse processo, mas sim fornecer simplesmente o suporte para que a 
criança através de seus processos psíquicos individuais atinja sua única e própria maturação. Ainda nesse estudo de Pavarini (apud NÉRI; CARVALHO, 2002), observou-se outra crença identificada nesses profissionais, é a de que a velhice vem acompanhada de dependência, doença e outras mazelas consideradas normais da idade (NERI; CARVALHO, 2002).

Diante de tais equívocos quanto à essência da função de cuidar e sobre o processo de envelhecimento, torna-se relevante atentar-se para o modo de percepção e atuação dos cuidadores frente ao ser idoso e aos cuidados demandados por ele. Tal percepção e maneira de assistir podem estar relacionadas à sua preparação para o exercício desse papel junto a pessoas que estejam passando por aquele processo.

No contexto atual o cuidador aprende com seu próprio fazer. Nesse fazer desenvolve percepções sobre si e sobre aqueles de quem cuida. Na relação cuidador-ser-cuidado, ocorre uma experiência mútua, cuja profundidade e percepção da mesma dependem do modo de compreensão e absorção de cada um dos atores. Se as percepções desenvolvidas pelos cuidadores ao longo de seu fazer constituem-se em parâmetros para o próprio ato de cuidar, torna-se relevante conhecê-las de forma mais precisa. Eis porque no tocante a esse tema nada mais pertinente do que buscar respostas para a questão central desse estudo, formulada nos seguintes termos: Qual a percepção de cuidadores de idosos institucionalizados sobre o processo de envelhecimento e a influência desta sobre o ato de cuidar?

\section{Material e Método}

\section{Objetivo e delineamento do estudo}

Trata-se de uma pesquisa transversal de tipo exploratória ${ }^{2}$, que teve por objetivo conhecer a percepção de cuidadores de idosos sobre o envelhecimento e sua influência sobre 0 ato de cuidar. $O$ presente estudo, quanto aos procedimentos técnicos utilizados, assumiu a forma de levantamento ${ }^{3}$.

\section{Universo do estudo}

A população estudada foi constituída por cuidadores de idosos que atuam em cinco Instituições de Longa Permanência do município de Governador Valadares - MG.

\section{Amostra}

A amostra foi constituída por 26 cuidadores de idosos que estavam presentes nas instituições participantes deste estudo, nos dias e horários em que foram programadas e realizadas as entrevistas.

\section{Coleta de dados}

Para a realização das entrevistas foram disponibilizadas salas iluminadas, contendo mesas e cadeiras, próximas ao posto de trabalho dos cuidadores. Antes de iniciar a entrevista os participantes 
foram informados sobre os objetivos da pesquisa e procedimentos aos quais seriam submetidos; assegurados do caráter confidencial de suas respostas e de seu direito de nãoidentificação; informados de que a pesquisa possui caráter voluntário e que todos participantes, mesmo após assinar o Termo de Consentimento Livre e Esclarecido, poderiam interromper o processo a qualquer momento caso não mais desejassem participar da pesquisa. Sendo a coleta de dados realizada no horário de expediente dos respondentes, estes foram ainda informados que poderia ocorrer interrupção momentânea da entrevista, em função de possíveis solicitações de atendimentos emergenciais aos internos.

As entrevistas foram realizadas por um único entrevistador no período de 04/07 a 15/08/2008. Estas foram realizadas em situação individual, registradas eletronicamente com prévia autorização dos entrevistados. Àqueles que não se sentiam confortáveis com o registro eletrônico era proposto que as resposta fossem anotadas no Roteiro Estruturado de Entrevista desenvolvido especialmente para este estudo. A utilização do referido roteiro teve por objetivo garantir a uniformidade quanto ao número e ordem das 35 questões dirigidas aos participantes que permitiram identificar: dados sóciodemográficos dos cuidadores; dados institucionais; percepções sobre o idoso e o processo de envelhecimento, com base na prática profissional cotidiana; e, as percepções sobre o "tornar-se" idoso e a própria velhice, como descrito abaixo.

1. Dados sociodemográficos: idade, sexo, escolaridade, estado civil, número de filhos, endereço, unidade de trabalho, vínculo com a instituição, meio de transporte, cargo, formação profissional, ocupação anterior à função exercida, salário na função anterior, motivo de escolha da atual profissão, salário na função atual, tempo na função atual, treinamentos recebidos;

2. Dados institucionais: natureza jurídica da instituição, objetivos da instituição, fundadores, data de fundação, número de internos, fontes de recursos para manutenção, processo utilizado na seleção de cuidadores, treinamentos oferecidos aos profissionais, abrangência regional, profissionais permanentes da equipe de saúde, profissionais voluntários, dificuldades encontradas, iniciativas de superação;

3. Perguntas relativas às percepções sobre o idoso e o processo de envelhecimento com base na prática profissional cotidiana: Com base na sua experiência profissional, como você caracteriza o ser idoso? Em sua experiência o que é saúde do idoso? Quais são as queixas mais frequentes dos idosos? Quais são as dificuldades que você encontra para o bom desempenho na atenção ao idoso? Que tipo de curso ou treinamento você considera que seria bom 
participar para aumentar ainda mais seu conhecimento quanto ao processo de envelhecimento, e ao cuidado com os idosos?

4. Perguntas do tipo autoavaliativas quanto à percepção sobre o "tornar-se" idoso e à própria velhice: O que significa a palavra "idoso" para você? O que é envelhecimento segundo o seu entendimento? O que representa a velhice para você? Como você imagina que será sua velhice? O que você tem feito ou programado para fazer, para que tenha uma velhice com maior qualidade de vida?

\section{Aspectos éticos}

A pesquisa foi submetida e aprovada pelo Comitê de Ética em Pesquisa (CEP) da Universidade através do parecer CEP/UNIVALE $42 / 2006$. Todos os indivíduos que aceitaram participar do estudo leram e assinaram um Termo de Consentimento Livre e Esclarecido (TCLE).

\section{Análise estatística}

As contribuições dos cuidadores, referentes aos dados sociodemográficos e aos dados institucionais, foram analisadas quantitativamente com o auxílio do programa SPHINX. As questões subjetivas, enfocando as percepções sobre o idoso e o processo de envelhecimento, com base na prática profissional cotidiana e, a autoavaliação dos entrevistados quanto à percepção sobre o "tornarse" idoso e à própria velhice, foram analisadas qualitativamente mediante o emprego da análise de conteúdo de Bardin (2009).

\section{Resultados e Discussão \\ Caracterização dos Participantes}

Dentre as características observadas nos cuidadores entrevistados, destaca-se o sexo feminino que perfaz $96,2 \%$ dos respondentes. Isto significa que apenas um dos profissionais é do sexo masculino. Quanto à idade desses cuidadores, sobressaem os que possuem entre trinta a trinta e cinco anos $(34,6 \%)$, seguidos por aqueles com idade menor que trinta anos $(26,9 \%)$ e de quarenta a quarenta e cinco $(15,4 \%)$. Em relação ao grau de instrução dos respondentes, predominam os que possuem segundo grau $(57,7 \%)$ com acréscimo de curso técnico de enfermagem. Os demais funcionários $(30,8 \%)$, que possuem curso superior não atuam diretamente nos cuidados diários com os idosos.

$\mathrm{O}$ alto percentual de mulheres como cuidadoras nos proporciona uma reflexão, sobre o papel de cuidar que a sociedade geralmente atribui à mulher. $O$ fato do cargo de cuidador ser ocupado em sua maioria pelo sexo feminino, torna-se preocupante. Em seu trabalho, o cuidador é levado a desenvolver atividades que exigem grande esforço físico como no caso dos banhos a pacientes, dentre outros. Assim, devido ao pouco número de cuidadores masculinos, as mulheres acabam por desenvolver tais atividades. Estas, ao serem 
somadas àquelas de sua segunda jornada de trabalho, na qual assumem o papel de esposa, zeladora do lar e dos filhos, contribuem para que a sobrecarga de atividades torne-se extrema (NAKATANI, 2003).

Quanto à descrita formação dos entrevistados, destaca-se os que possuem segundo grau com formação técnica em enfermagem. Entretanto, tal formação está direcionada a atender as necessidades físicas dos idosos, sem considerar os aspectos emocionais, culturais e sociais que os mesmos trazem para compor o cenário de realização das respectivas atividades.

\section{Análise sobre a formação do cuidador}

Segundo Duarte, Melo e Azevedo (2008) e Born (2006), não há uma regulamentação específica quanto à formação do cuidador, nem quanto aos requisitos para a contratação e atuação dos mesmos nas instituições. Com base nos dados coletados constatou-se que essa situação condiz com a realidade. Observou-se que a maioria dos entrevistados $(92,3 \%)$ recebeu treinamentos apenas depois de ter sido realizada a contratação. Segundo os respondentes, os treinamentos foram organizados pelas instituições, tendo ocorrido nas mesmas ou em outros ambientes como hospitais, SESI e Universidade. Contudo, não há como definir se tais treinamentos ou formações foram adequados ou não para o exercício pleno da profissão. Convém salientar que $7,7 \%$ dos entrevistados não receberam nenhuma formação para atuar junto aos idosos nem mesmo depois de estarem atuando na função.

Tomando-se por base a literatura, pode-se afirmar que os idosos institucionalizados estão sendo cuidados por profissionais que não possuem qualificação condizente com as necessidades do público assistido. Esse fator implica diretamente na qualidade de vida dos internos, além de descumprir os direitos do público em questão conforme a Lei no 10.741 que estabelece o Estatuto do Idoso (BRASIL, 2007). Tal descuido na preparação dos cuidadores fere ainda a Política Nacional de Saúde do I doso (PNSI) que prevê atenção especial aos profissionais de saúde que cuidam dos idosos (RIBEIRO; FERREIRA; FERREIRA; MAGALHÃES; MOREIRA, 2008).

Referente às atividades realizadas com os idosos nas instituições, $80,8 \%$ estão direcionadas às necessidades primárias dos internos. Tal prática é exercida por cuidadores, que responderam proporcionar auxílio direto aos idosos em higienização, medicação, alimentação e outros. Destes, somente $7,7 \%$ além de cuidarem dos cuidados primários, participam da vida social do ser cuidado, saem juntos, vão à missa, trenzinho, festas e outras atividades consideradas relevantes para o bem-estar do idoso.

Como constatado, a maioria dos profissionais cuida das necessidades primárias dos idosos e apenas a minoria participa da vida social, emocional e de lazer dos mesmos. Esse fato aponta para a 
necessidade dos cuidadores ampliarem seus conhecimentos, melhorar sua concepção em torno do envelhecimento e desmistificar a suposta ideia de que todo idoso traz consigo a dependência. É essencial que esse profissional esteja preparado não para ser apenas um "companheiro" do idoso, mas para criar condições de forma que este possa melhorar sua qualidade de vida. De acordo com Filho e Sitta (2002), é preciso que o profissional de saúde entenda o processo de envelhecimento e sua diversidade.

Quanto aos motivos apresentados pelos cuidadores de uma má manutenção da saúde bucal dos idosos, $53,8 \%$ são inadequados por revelarem uma inabilidade no trato com os internos. I nabilidade essa decorrente de um despreparo dos cuidadores $(23,1 \%)$ ou por se tratar de profissionais que não são comprometidos com seu trabalho $(30,8 \%)$ culpabilizando o meio externo pela falta de cuidado. Esse não comprometimento é expresso pelos cuidadores nos seguintes termos:

Poucos profissionais para muito trabalho e resistência dos idosos (Feminino, 30 anos).

Alguns não aceitam fazer a higienização (Feminino, 40 anos). Resistência dos idosos (Feminino, 29 anos).

Os cuidadores que revelam uma inabilidade por despreparo justificam o não cuidado das seguintes formas:

Resistência porque alguns não têm prótese. Os que têm dentes usam escova, pasta (Feminino, 32 anos).

A patologia do idoso [...] não permitindo os cuidados (Feminino, 24 anos).

Resistência mais por parte dos homens. Não abrem a boca (Feminino, 26 anos).

Ainda em relação à inadequada manutenção da saúde bucal dos idosos, 19,2\% dos cuidadores deram respostas descontextualizadas. Tal descontextualização é decorrente do fato de alguns não estarem diretamente ligados aos serviços de cuidar da saúde bucal do idoso, ou por não saberem responder de forma direta a questão.

Nenhuma (Feminino, 30 anos).

Trabalho no plantão noturno. Geralmente este trabalho é realizado durante o dia (Feminino, 39 anos).

A maioria é desdentada, mas deixam realizar a escovação da língua e bochechas (SIC) (Feminino, 32 anos).

Diante dos relatos é possível perceber que grande parte $(53,8 \%)$ não respondeu à ausência de cuidados como uma dificuldade própria. Assim, o não-comprometimento e o despreparo apesar de não aparecerem explicitamente descritos em suas respostas, foram identificados. Tal identificação foi provável devido às justificativas dos 
respondentes não serem consideradas relevantes à ausência de cuidados, o que de fato tenderiam a estar associadas ao descaso e despreparo.

Esse dado diz respeito à situação da saúde bucal dos idosos no Brasil, descrita por Colussi e Freitas (2002). Segundo eles, tal situação é precária devido à incapacidade física do idoso frente à demanda dos cuidados. Portanto, se não cabe ao cuidador realizar esses cuidados e promover a autonomia permitindo a colaboração da parte envolvida, não há outra forma de progredir quanto a esse quadro.

\section{Respostas dos cuidadores em relação às suas motivações, percepções e sentimentos atribuídos ao trabalho}

Dentre as motivações que levaram os cuidadores a trabalhar nessa área, destacam-se o interesse em conhecer a realidade dos idosos através do contato diário e sentimentos de afinidade com esse grupo populacional. Estes correspondem a $61,5 \%$ dos motivos para a escolha da profissão. Os entrevistados expressam essa situação nos seguintes termos:

Sempre tive vontade de trabalhar com idosos (Feminino, 40 anos).

Gosto da profissão e de cuidar de idosos (Feminino, 39 anos).

Conhecia a necessidade dos internos, já os visitava e isso me interessou (Feminino, 32 anos).

Além da afinidade com a profissão, a oportunidade $(19,2 \%)$, e num mesmo índice a necessidade $(19,2 \%)$ de trabalho, constituíram-se em outros motivos significativos de ingresso na profissão. Essas ocorrências foram expressas conforme abaixo:

\footnotetext{
Oportunidade de trabalho, pois já trabalhava na área (Feminino, 40 anos).

Só vim cobrir férias e acabei permanecendo na profissão (Feminino, 48 anos).

Necessidade de trabalho (Feminino, 30 anos).

Por causa do emprego, estava precisando trabalhar (Feminino, 29 anos).
}

De acordo com Boff (1999), o cuidar é uma dimensão essencial do ser. O que se assemelha ao dizer de Winnicott (1999), quando este se refere ao estado de sensibilidade aguçada da mãe, que surge antes mesmo do seu filho nascer, isto é, durante a gravidez. Seguindo o raciocínio dos autores, pode-se dizer que o processo de cuidar do idoso exige algumas habilidades e virtudes indispensáveis para o perfil daquele que cuida e supõe-se que as fundamentais seriam: o amor, o carinho, o zelo, a paciência e a dedicação. Tais habilidades foram identificadas no discurso da maioria dos cuidadores 
entrevistados. Estes responderam ter a afinidade e o interesse como principais motivos para trabalhar nessa área. Consequentemente, tais motivos criam possibilidades de construção de outras aptidões consideradas necessárias.

Em relação à percepção dos cuidadores no que se refere ao exercício de sua profissão, observou-se que $88,5 \%$ dos entrevistados possuem uma percepção positiva da mesma. Tal positividade está expressa através de termos que demonstram afeto e amor pelos idosos, sentimentos de importância atribuída à profissão e ao desenvolvimento dos internos. A esse título vale citar alguns fragmentos de depoimentos que ilustram com maestria tal situação.

\footnotetext{
Enorme importância, essencial para o interno, aumento da funcionalidade (Feminino, 26 anos).

Me sinto importante, pois faço o que gosto, faço por amor (Feminino, 45 anos).

Gratificante, gosto. Acho bom ao solucionar algum problema [...] atenção aos idosos (Feminino 42 anos).
}

Diferentemente, $11,5 \%$ dos cuidadores, percebem a profissão de forma negativa, referindo-se à mesma como difícil e exigente com aqueles que a exercem. A exigência citada está relacionada às questões de equilíbrio emocional e flexibilidade de pensamento, por se estar lidando com sujeitos provenientes de culturas e condições sociais diversificadas, bem como de condições físicas e emocionais particulares. Também dentro dessa categoria, estão enquadrados aqueles que apresentaram queixas em relação à sobrecarga do trabalho, complexidade e retorno. Em outros termos, entendem que a evolução da situação dos pacientes no que se refere ao serviço executado é demorada e muitas vezes, inexistente.

É complexo, o retorno é vagaroso. Às vezes o trabalho feito parece que não refletiu em nada. Assim percebo meu trabalho e dos funcionários que também dão assistência (Feminino, 47 anos).

Boa, difícil, exige muito da gente. Tem que ter paciência e mente aberta (Feminino, 28 anos).

Acho o trabalho pesado (Feminino, 32 anos).

Os dados coletados reforçam a pertinência das observações de Born (2006), segundo as quais inexistem pré-requisitos estabelecidos para a contratação de cuidadores de idosos institucionalizados. Tal fato pode ajudar a entender o pequeno percentual de profissionais que sentem uma exigência do trabalho relacionada à complexidade do público que é assistido, ou seja, os idosos. Com efeito, na medida em que não é cobrada a qualificação do cuidador, também não é sentida pelo mesmo a dimensão da necessidade. 
Considerando o verdadeiro sentimento de afinidade e amor, que antecede o cuidador ao exercício de sua profissão, a falta de qualificação ainda se reflete no fato de a maioria $(88,5 \%)$ dos entrevistados, enxergarem a profissão de forma positiva. Tal consideração se faz pertinente devido à visão do cuidador frente à profissão ser mencionada de forma por vezes "romântica". Dessa forma, atribuem à mesma sentimentos de afetividade sem considerar a emergência de atendimento a fatores que comprometem a saúde e o bem-estar do idoso, passando-Ihes despercebidos. É em referência a esses fatores que o olhar do cuidador deve ser diferenciado, isto é, estar voltado às atenções específicas que só competem ao seu cargo.

\section{Como os cuidadores definem o ser idoso e de que maneira se projetam para a velhice}

Tendo como objetivo descrever o modo como os cuidadores percebem o processo de envelhecimento de si e do outro, destacouse, dentre os dados obtidos, que $53,8 \%$ dos cuidadores possuem uma visão negativa em relação à maneira de definir o ser idoso. Essa percepção foi explicitada pelos cuidadores da seguinte forma:

Aquele que não tem mais perspectiva de vida e por isso não tem mais sonhos, principalmente na instituição (Feminino, 45 anos).

$\mathrm{Na}$ maioria das vezes pessoas calejadas [...] Passou pela vida e não realizou o que gostaria (Feminino, 32 anos).

Numa posição contrária a essa mesma definição, 38,5\% dos cuidadores possuem uma visão positiva representando o ser idoso nos seguintes termos:

Ser feliz, aceitar a realidade que se encontra (Feminino 32 anos).

Ser idoso é ter qualidade de vida [...] é o que tentamos proporcionar a eles (Feminino 24 anos).

Segundo Trentini, Chachamovich, Figueiredo, Hirakata e Fleck (2006), os cuidadores de idosos têm uma percepção deturpada em relação ao processo de envelhecimento. Os autores também ressaltam a tendência que esse profissional tem em enxergar de forma mais negativa a velhice do que o próprio idoso. Tal fator coincide com o estudo de Pavarini (apud NERI; CARVALHO, 2002) apresentado na presente literatura, no qual foram observadas pela autora crenças equivocadas dos cuidadores em relação à velhice. Em relação à visão ou projeção de si aos 60 anos de idade, 57,7\% dos cuidadores utilizaram-se do bom humor em suas respostas. Suas expectativas são de que chegarão a essa fase, mentalmente e fisicamente ativos desfrutando de autonomia. Alguns entrevistados 
indecisos $(26,9 \%)$ afirmaram não conseguir se imaginar uma pessoa "velha", ou não ter se programado para a velhice. Já $15,4 \%$ dos respondentes projetaram-se de forma negativa, imaginaram-se tornar idosos chatos, dependentes e mal humorados. Tais expressões negativas podem ser ilustradas a seguir:

Enjoado, ranzinzo, dependendo de cuidados como eles (Masculino, 30 anos).

A mera indecisão apresentada por alguns dos cuidadores pode ser verificada nos seguintes fragmentos:

Não sei, não planejo nada, não junto dinheiro... Vivo o hoje (Feminino, 42 anos).

Acho que vou ser uma velha boa. Não sei... Acho que vou ser rabugenta (Feminino, 32 anos).

Diferentemente, o exemplo da positividade é expressa pela maioria dos entrevistados nos respectivos termos:

Vou estar idoso com uns 90 anos, com 60 ainda vou estar jovem, andando de moto (Feminino, 40 anos).

Vou ser boa, ativa, fazer exercício físico, alimentação, física (Feminino, 26 anos).

Espero que eu tenha uma vida ativa, me sentindo bem fisicamente e mentalmente (Feminino, 39 anos).

Aparentemente pode-se considerar contraditório o fato de a maioria dos cuidadores definirem o ser idoso de forma negativa, sendo essa mesma maioria a se projetar de forma positiva como futuros idosos. Por outro viés, ao analisar tal situação pode-se destacar uma concordância existente entre os fatos. O primeiro pode influenciar 0 segundo, na medida em que a visão atual negativa constrói defesas para não se projetarem como pessoas "velhas" tendo as possíveis e naturais fragilidades. Fragilidades, que como já dito, são naturais com a chegada da velhice e não se deve descartar a capacidade do idoso de ter autonomia diante delas.

Portanto, a inesperada correlatividade contribui para que esses profissionais formem uma percepção equivocada sobre o envelhecimento. Isto, porque ela apresenta um olhar do cuidador não voltado às esperanças em relação ao idoso ou futuramente a ele próprio de viver melhor com suas fragilidades, mas um olhar temeroso que o faz recuar e querer estar imune às possíveis e naturais alterações em seu estilo de vida. Ressalta-se que tal posição também distancia esse profissional de uma preparação psicológica adequada, seja ela para enfrentar os cuidados com as pessoas idosas ou para se tornarem idosos com maior qualidade de vida no futuro. 


\section{Considerações Finais}

No desenvolvimento de todo o trabalho, destacou-se alguns aspectos que poderiam influenciar na percepção do cuidador sobre o envelhecimento. Portanto, conclui-se após levantamento dos dados que tais aspectos como a falta de preparo, de qualificação, atenção, suporte emocional e social, influenciam de fato na formação da percepção e consequentemente no ato de cuidar desse profissional. Percepção que ao ser formada, comprovou ser marcada por equívocos, negatividade, confusões e muitas vezes "fantasias" do cuidador em relação ao processo de envelhecimento.

Considera-se que tais definições implicam diretamente na qualidade dos cuidados prestados aos idosos. Alguns resultados, explicam esse fato como, por exemplo, aqueles que relatam a falta de cuidado com a saúde bucal do idoso, e o suprimento às suas necessidades fisiológicas encontrado em destaque. Por outro lado, não se pode deixar de realçar os resultados que indicaram uma motivação primária dos profissionais cuidadores a exercerem sua profissão. Motivação assim denominada, por ser constituída de sentimentos peculiares como a afinidade e o amor tidos por eles antes mesmo da prática de cuidar.

De acordo com Winnicott (1999), o desejo de cuidar deve anteceder a sua prática. A unidade que se estabelece na relação mãe-bebê é devido ao fato de que o desejo de cuidar da mãe está acoplado à necessidade do filho de ser cuidado. Contudo, tendo como base a teoria de Winnicott, a qual apresenta o desejo de cuidar da mãe tido normalmente como natural e constante em relação ao seu bebê até que ele se desenvolva estruturalmente, o mesmo não se pode afirmar sobre os sentimentos positivos manifestados pelos cuidadores. Isso se deve ao fato de que tais sentimentos não permearam suas percepções e nem o trabalho por eles desenvolvido.

Assim, essas emoções podem não ser permanentes se elas ocorrerem de forma isolada, isto é, sem receber o devido suporte para o seu desenvolvimento, direção e conservação. Para que o desejo de cuidar implícito na afinidade e no amor sentidos pelos cuidadores faça naturalmente parte da conduta desses profissionais, primeiramente se faz necessário que estes recebam a adequada sustentação física e psíquica a qual Winnicott denomina de "holding", que seria a função materna de sustentação.

A respectiva ideia que consiste em fornecer o adequado suporte, ou melhor, o "holding" para o cuidador, repercute na ideia apresentada por Campos (2006). Esse autor, com base na teoria de Winnicott, fundamentou-se na visão de que o próprio grupo de cuidadores pudesse se auto-sustentar, o que se referia à construção de um ambiente acolhedor e estruturante entre esses profissionais, com 0 intuito de que o "holding" se desenvolvesse a partir deles e fosse transferido por eles através do ato de cuidar. 
Contudo, diferentemente do objeto de estudo dessa pesquisa, o público analisado por Campos era formado por uma equipe de profissionais da saúde que se constituíam numa equipe multidisciplinar, proposta por um programa de atendimento a pacientes hipertensos. Tratava-se de profissionais de diversos saberes, com formação superior e que também exerciam o papel de cuidadores do grupo de hipertensos. Reuniam-se para discutir e analisar o atendimento que prestavam àqueles pacientes, assim como os relacionamentos estabelecidos entre eles, colegas de trabalho.

No entanto, considerando a desqualificação e o contexto do ambiente em que o cuidador analisado está inserido, a ideia de Campos só se fará útil para a proposta deste trabalho, estando ela como segunda alternativa. Isto é, para que o grupo de cuidadores de idosos institucionalizados se auto-sustente ou que desenvolva entre eles um ambiente de afetividade, cuidados mútuos, trocas de experiências e acolhimento, sugere-se que os mentores responsáveis pela sua formação (psicólogos, enfermeiros, médicos, assistentes sociais) forneçam primeiramente sua devida capacitação.

Capacitação, que enquanto ausente, afetou prejudicialmente a percepção do profissional cuidador em relação ao processo de envelhecimento, trazendo também consequências para sua maneira de cuidar. É por esse caminho que se propõe através dessa pesquisa oferecer um "holding" suficiente para o cuidador, aquele que seja capaz de atender suas necessidades iniciais como a preparação profissional e pessoal. Somente dessa forma ele conseguirá estabelecer uma unidade em seu trabalho com o idoso e construir entre eles uma relação "suficientemente boa", assim como diria Winnicott.

\section{Referências Bibliográficas}

ANVISA - Agência Nacional de Vigilância Sanitária. Resolução da Diretoria Colegiada - RDC 283, 25/09/2005.

BARDIN, L. Análise de conteúdo. 5.ed. Coimbra: Geográfica, 2009. BERGER, K. S. I nício da Idade Adulta: O Desenvolvimento Biossocial. In: ____. O Desenvolvimento da pessoa: da infância à terceira idade. 5. ed. Rio de Janeiro: LTC, 2003, p. 298-313.

BOFF, L. Cuidado: o ethos do humano. In: Saber cuidar: ética do humano - compaixão pela terra. Petrópolis, RJ: Vozes, 1999, p. 33-42.

BORN, T. A formação de cuidadores: acompanhamento e avaliação. In: Seminário Velhice Fragilizada. São Paulo: SESCSP, nov. 2006. Disponível em: <http://www. sescsp.org. br/sesc/images/upload/conferencias/366.rtf >. Acesso em: 11 abr. 2009. 
BORN, T; BOECHAT, N. S. A qualidade dos cuidados ao idoso institucionalizado. In: FREITAS, E. V; PY, L.; CANÇADO, F. A. X.; DOLL, J.; GORZONI, M. L. Tratado de Geriatria e Gerontologia. Rio de Janeiro: Guanabara Koogan, 2002. p.768-77.

BRASIL. Ministério da Saúde. Política Nacional de Saúde do I doso - Portaria 1395/GM. Brasília, 1999. Disponível em: $<$ http//WWW.saude.gov.br> Acesso em 20/04/2010.

BRASIL. Portaria n. 810. Normas para Funcionamento de Casas de Repouso, Clínicas Geriátricas e Outras Instituições Destinadas ao Atendimento ao I doso. 22/09/1989, Publicado no Diário Oficial de 27/09/2007.

BRASIL. Portaria n. 73. Normas de Funcionamento de Serviços de Atenção ao I doso no Brasil. 2001 maio 10.

BRASIL. Presidência da República. Lei $n^{\circ} \mathbf{1 0 . 7 4 1}$, de $1^{\circ}$ de Outubro de 2003. Brasília (DF), 2003.

BRASIL. Instituto Brasileiro de Geografia e Estatística - IBGE. Pesquisa nacional por amostra de domicílios, Brasília: IBGE, 2005. [S.I.], 2007.

BRASIL. Portaria do Gabinete do Ministro do Estado da Saúde de no 2.528, de 19 de outubro de 2006, que aprova a Política Nacional de Saúde da Pessoa Idosa. Diário Oficial (da) República Federativa do Brasil, Brasília, DF, 2006.

BRITO, F. C. de; RAMOS, L. R. Serviço de Atenção à Saúde do Idoso. In: NETTO, M. P. Gerontologia: A Velhice e o Envelhecimento em Visão Globalizada. São Paulo: Atheneu, 2002, p. 394-402.

CAMPOS, E. P. Equipe de saúde: cuidadores sob tensão. Epistemosomática, Belo Horizonte, v. 3, n. 2, dez. 2006. Disponível em: $<$ http://pepsic. bvs-

psi.org.br/scielo.php?script=sci_arttext\&pid=S1980-

$20052006000200005 \&$ lng $=$ pt\&ñm=iso >. Acesso em: 23 jan. 2009.

COLUSSI, C. F.; FREITAS, S. F. T. de. Aspectos epidemiológicos da saúde bucal do idoso no Brasil. Cadernos de Saúde Pública, Rio de Janeiro, v. 18, n. 5, out. 2002. Disponível em: <http://www.scielo.br/scielo. php?script=sci_arttext\&pid=S0102-

311X2002000500024\&lng=pt\&nrm=iso>. Acesso em: $31 \mathrm{dez} .2008$.

DUARTE, J. E.; MELO, R. V. de; AZEVEDO, R. S. Cuidando do cuidador. In: MORAES, E. N. de. Princípios básicos de geriatria e gerontologia. Belo Horizonte: Coopmed, 2008, p. 371-379.

FILHO, W. J.; SITTA, M. do C. Interprofissionalidade. In: NETTO, M. P. Gerontologia: A Velhice e o envelhecimento em Visão Globalizada. São Paulo: Atheneu, 2002, p. 440-450.

FRIEDAN, B. Desenvolvimento fisico e cognitivo na terceira idade. In: PAPALIA, D. E.; OLDS, S. W. Desenvolvimento humano. Porto Alegre: Artes Médicas Sul, 2000, p. 492-521.

GIL, A. C. Como elaborar projetos de pesquisa. 4. ed. São Paulo: Atlas, 2002. 
HERÉDIA, V. B. M.; CASARA, M. B.; CORTELLETTI, I. A.; RAMALHO, M. H.; SASSI, A.; BORGES, M. N. A realidade do idoso institucionalizado. In: Textos sobre envelhecimento. UnATI/UERJ, v. 7, n. 2, p. 9-31, 2004 jul./dez

J ORGE, M. H. P. de M.; LAURENTI, R.; LIMA-COSTA, M. F.; GOTLIEB, S. L. D.; FILHO, A. D. P. C. A mortalidade de idosos no Brasil: a questão das causas mal definidas. Epidemiologia e serviços de saúde. Brasília, v. 17, n. 4, dez. 2008. Disponível em: <http://scielo.iec. pa.gov.br/scielo.php?script=sci_arttext\&pid=S1679 -49742008000400004\&lng=pt\&nrm=iso>. Acesso em: 19 abr. 2009. LIMA-COSTA, M. F.; CAMARANO, A. A. Demografia e epidemiologia do Envelhecimento no Brasil. In: MORAES, E. N. de. Princípios básicos de geriatria e gerontologia. Belo Horizonte: Coopmed, 2008, p. 319.

NAKATANI, A. Y. K.; SOUTO, C. C. S.; PAULETTE, L. M.; MELO, T. S.; SOUZA, M. M. Perfil dos cuidadores informais de idosos com déficit de autocuidado atendidos pelo Programa de Saúde da Família. Revista Eletrônica de Enfermagem, Goiânia, v. 5, n. 1, ago. 2003. Disponível em: <http://www.revistas.ufg.br/index. php/fen/article/viewFile/773/863 Acesso em: 20mai. 2009

NERI, A. L.; CARVALHO, V. A. M. de L. e. O Bem-estar do cuidador: Aspectos Psicossociais. In: FREITAS, E. V. de; P. Y, L.; NERI, A. L.; CANÇADO, F. A. X.; GORZONI, M. L.; ROCHA, S. M. da. Tratado de geriatria e gerontologia. Rio de Janeiro: Guanabara Koogan, 2002, p.778-790.

NETTO, M. P. O Estudo da velhice: histórico, definição do campo e termos básicos. In: FREITAS, E. V. de; PY, L.; CANÇADO, F. A. X.; DOLL, J.; GORZONI, M. L. Tratado de geriatria e gerontologia. $2^{\circ}$ ed. Rio de Janeiro: Guanabara Koogan, 2006, p. 2-12.

ORGANIZACION MUNDIAL DE LA SALUD. Grupo científico sobre la epidemiologia del envajacimiento. Genebra, 1983.

PASCHOAL, S. M. P. Epidemiologia do envelhecimento. In: NETTO, M. P. Gerontologia: a velhice e o envelhecimento em visão globalizada. São Paulo: Atheneu, 2002, p. 26-43.

PELLEGRINI, V. M. C.; JUNQUEIRA, V. Trajetórias das políticas de saúde: a saúde coletiva e o atendimento ao idoso. In: NETTO, M. P. Gerontologia: a velhice e o envelhecimento em visão globalizada. São Paulo: Atheneu, 2002, p. 373-382.

POLLO, S. H. L.; ASSIS, M. Instituições de longa permanência para idosos - ILPIS: desafios e alternativas no município do Rio de Janeiro.

Rev. Bras. Geriatr. Gerontol., v. 11, n. 1, Rio de Janeiro 2008. Disponível em: <http://www.unati.uerj.br/tse/scielo.php?script=sci_arttext\&pid=S18 09-98232008000100004\&lng=pt\&nrm=iso> Acesso em: 23 abr. 2010. 
RIBEIRO, M. T. de F.; FERREIRA, R. C.; FERREIRA, E. F.; MAGALHÃES, C. S. de; MOREIRA, A. N. Perfil dos cuidadores de idosos nas instituições de longa permanência de Belo Horizonte, MG. Ciência e Saúde Coletiva, v. 13 n. 4, Rio de Janeiro, Jul./Ago. 2008.

<http: //www.scielo.br/scielo.php?script=sci_arttext\&pid=S1413-

$81232008000400025 \&$ Ing=en\&nrm=iso>. Acesso em: 26 abr. 2009.

SALIBA, N. A.; MOIMAZ, S. A. S.; MARQUES, J. A. M.; PRADO, R. L. do. Perfil de cuidadores de idosos e percepção sobre saúde bucal. Revista I nterface - comunicação, saúde, educação, Botucatu, v. 11, n. 21, abr. $2007 . \quad$ Disponível em: <http: //www.scielo.br/scielo.php?script=sci_arttext\&pid=S1414$32832007000100005 \& l n g=e n \& n r m=i s o>$. Acesso em: 28 jan. 2009. SILVA, M. C. O processo de envelhecimento no Brasil: desafios e perspectivas. Textos sobre Envelhecimento, v. 8 n. 1, p. 43-60, , 2005 jan./abr.

TRENTINI, C. M.; CHACHAMOVIC, E.; FIGUEIREDO, M.; HIRAKATA, V. N.; FLECK, M. P. de A. A percepção de qualidade de vida do idoso avaliada por si próprio e pelo cuidador. Estudos de psicologia (Natal), Natal, v. 11, n. 2, ago. 2006. Disponível em: <http://www.scielo.br/scielo.php?script=sci_arttext\&pid=S1413294X2006000200008\&lng=pt\&nrm=iso >. Ačsso em: 10 jul. 2009. WINNICOTT, D. W. O ambiente e os processos de maturação. Porto Alegre: Artes Médicas, 1982.

WINNICOTT, D. W. Os bebês e suas mães. 2.ed. São Paulo: Martins Fontes, 1999.

\section{Endereço para correspondência}

Aline Melo Oliveira Sampaio

Centro de Atenção Psicossocial (CAPS), Av Santa Izabel no 627, Bairro Monte Castelo, CEP 45995-000, Teixeira de Freitas - BA, Brasil.

Endereço eletrônico: alinemelopsi2008@hotmail.com

Fernanda Nunes Rodrigues

Universidade Vale do Rio Doce, Rua Israel Pinheiro, 2000, Bairro Universitário, CEP 35020-220, Governador Valadares - MG, Brasil.

Endereço eletrônico: fernanda_psique@hotmail.com

Valquiria Gonçalves Pereira

Universidade Vale do Rio Doce, Rua Israel Pinheiro, 2000, Bairro Universitário, CEP 35020-220, Governador Valadares - MG, Brasil.

Endereço eletrônico: valquiria.pereira@hotmail.com

Suely Maria Rodrigues

Universidade Vale do Rio Doce, Rua Israel Pinheiro, 2000, Bairro Universitário, CEP 35020-220, Governador Valadares - MG, Brasil.

Endereço eletrônico: badi@univale.br

Carlos Alberto Dias

Universidade Vale do Rio Doce, Rua Israel Pinheiro, 2000, Bairro Universitário, CEP 35020-220, Governador Valadares - MG, Brasil.

Endereço eletrônico: cdias@univale.br 
Aline Melo Oliveira Sampaio, Fernanda Nunes Rodrigues, Valquiria Gonçalves Pereira, Suely Maria Rodrigues, Carlos Alberto Dias

Recebido em: 03/12/2009

Reformulado em: 29/04/2010

Aceito para publicação em: 30/04/2010

Acompanhamento do processo editorial: Ana Maria Lopez de Calvo Feijoo

\section{Notas}

*Psicóloga

**Graduanda em Psicologia da Universidade Vale do Rio Doce - UNIVALE; Bolsista de Iniciação Científica da FAPEMI G

***Graduanda em Psicologia da Universidade Vale do Rio Doce - UNIVALE; Bolsista de Iniciação Científica da FAPEMI G

**** Odontóloga, Doutora em Saúde Coletiva, Professora Adjunta da Universidade Vale do Rio Doce - UNIVALE

*****Psicólogo, Doutor em Psicologia Clínica, Professor Adjunto da Universidade Vale do Rio Doce - UNIVALE

${ }^{1}$ Este trabalho foi apoiado pela Fundação de Amparo à Pesquisa do Estado de Minas Gerais (FAPEMIG).

${ }^{2}$ A pesquisa exploratória tem como objetivo proporcionar maior familiaridade com o problema, com vistas a torná-lo mais explícito ou a constituir hipóteses. [...] objetivo principal o aprimoramento de idéias ou a descoberta de intuições. [...] envolvem: (a) levantamento bibliográfico; (b) entrevistas com pessoas que tiveram experiências práticas com o problema pesquisado: e (c) análise de exemplos que “estimulem a compreensão (GIL, 2002, p. 41).

${ }^{3}$ Trata-se de uma interrogação direta das pessoas cujo comportamento se deseja conhecer. Basicamente procede-se à solicitação de informações a um grupo significativo de pessoas acerca do problema estudado para, em seguida, mediante análise quantitativa, obterem-se as conclusões correspondentes aos dados coletados (GIL, 2002, p. 50). 